\title{
Behavioral and Psychological Factors Associated with 12-Month Weight Change in a Physical Activity Trial
}

\author{
Melissa A. Napolitano ${ }^{1}$ and Sharon Hayes ${ }^{2}$ \\ ${ }^{1}$ Departments of Kinesiology and Public Health and Center for Obesity Research and Education, Temple University, \\ 3223 North Broad Street, Suite 175, Philadelphia, PA 19140, USA \\ ${ }^{2}$ Center for Obesity Research and Education, Temple University, 3223 North Broad Street, Suite 175, Philadelphia, PA 19140, USA
}

Correspondence should be addressed to Melissa A. Napolitano, napolita@temple.edu

Received 1 June 2010; Revised 16 October 2010; Accepted 9 November 2010

Academic Editor: Neil King

Copyright ( $) 2011$ M. A. Napolitano and S. Hayes. This is an open access article distributed under the Creative Commons Attribution License, which permits unrestricted use, distribution, and reproduction in any medium, provided the original work is properly cited.

\begin{abstract}
Examining behavioral and psychological factors relating to weight stability over a 1-year period is of public health importance. We conducted a physical activity $(\mathrm{PA})$ intervention trial for women $(N=247$; mean age $=47.5 \pm 10.7$; mean $\mathrm{BMI}=28.6 \pm 5.3)$ in which participants were assigned to one of three groups (two PA and one contact-control). By Month 12, participants achieved $140.4 \pm 14.82 \mathrm{~min}$ of $\mathrm{PA} /$ week, with no group differences. Weight status change from baseline to Month 12 was categorized: no change $(N=154 ; 62.4 \%)$; increase $(N=34 ; 13.8 \%)$; decrease $(N=59 ; 23.9 \%)$. Discriminant function analyses indentified two statistically significant dimensions associated with weight change. Dimension 1 was positively weighted by mood (0.73) and self-efficacy (0.79); dimension 2 was positively weighted to change in physical activity (0.58) and fat consumption (0.55). Results provide further evidence for the importance of behavior in long-term weight maintenance, particularly physical activity and dietary fat. These findings also provide evidence for the importance of addressing psychosocial variables, in particular depressed mood and self-efficacy.
\end{abstract}

\section{Introduction}

The importance of being physically active has been well documented from a public health perspective, with increased activity associated with reduced risk for the development of chronic health conditions like cardiovascular disease [14]. Researchers have also reported positive mental health outcomes ranging from improved cognition to decreased depression $[5,6]$. Additionally, there is a strong association between physical activity and weight management $[7,8]$. Although a minimum of 150 minutes per week of moderate intensity activity is suggested to reduce health risks [9], some researchers have reported that more activity may be necessary to prevent weight gain [7] and promote weight loss or prevent weight regain after a significant loss [10-12].

It is notable that physical activity behavior has been shown to distinguish those who are successful at maintaining weight loss [13]. Other important behavioral factors associated with weight management include disinhibited eating [12, 13], low-fat diet [14], fruit and vegetable intake [15], and self-weighing [12]. Although these behavioral variables are helpful in determining who might be more successful at weight management, they do not account for all the variance observed. As a result, researchers have also examined psychosocial variables to determine how to improve weight control outcomes.

Psychosocial factors encompass many different domains, including depressed mood, stress, and social support. Although the literature is mixed regarding the exact direction of the relationship between mood and weight, many studies report an association. According to results of the National Weight Control Registry, less depressive symptomatology was associated with significant long-term weight loss maintenance (i.e., $\geq 30 \mathrm{lbs}$ weight loss maintained for at least 1 year) [12]. Prospective work suggests that while baseline depressive symptoms negatively influence weight over time, baseline weight does not have a direct effect on one's mood [16]. However, in the context of purposeful weight loss, 
successful loss is associated with improved $\operatorname{mood}[17,18]$. In addition to depressed mood, perceived stress has been linked with weight [19]. For example, lower ratings of baseline stress were associated with greater weight loss in one study [20]. However, the literature is mixed with some studies failing to find an association between perceived stress and body weight [21]. Finally, social support is another psychosocial variable that has been shown to be associated with improvements in weight and physical activity behavior (e.g., [22]). Psychological factors like depression and stress may interact with other theory-based variables like selfefficacy to promote participant behavior change that is associated with weight loss.

With regard to physical activity promotion and weight management, Social Cognitive Theory (SCT; [23]) and the Transtheoretical Model of Change (TTM; [24]) are discussed frequently within the literature and used to tailor interventions (e.g., $[25,26])$. Both SCT and the TTM emphasize selfefficacy or one's confidence in making a particular behavioral change. Self-efficacy (eating and exercise-related) has been shown to be predictive of short-term weight change $[27,28]$. Additionally, self-efficacy has been shown to be a critical intermediate variable associated with physical activity and weight loss maintenance [29]. The TTM also highlights other constructs like decisional balance, or the pros and cons of behavior change, and the processes of change (cognitive and behavioral) $[30,31]$. Decisional balance and processes of change have been associated with increased physical activity and weight loss [27, 29]. However, participation in an exercise promotion trial may not always improve all theoretical constructs (e.g., [32]).

Overall, theory-based interventions targeting physical activity and body weight have been shown to be largely effective, and these interventions have been delivered via a number of channels including face-to-face, mailings, and the Internet [33-37]. Despite these studies, additional work is needed to determine the ideal components of interventions designed to promote physical activity and weight loss. In particular, there is a continued need to clarify the roles of behavioral and psychosocial variables that affect physical activity and weight management.

The Women's Wellness Project was designed to examine the efficacy two print-based physical activity promotion programs for women [35]. In this project, women were randomly assigned to one of three groups: (1) Choose to Move (CTM), a print-based physical activity intervention designed specifically for women, (2) JumpStart, a motivationally tailored print-based intervention, or (3) Wellness contactcontrol group. The interventions (see below) focused on the adoption on maintenance of physical activity and did not include calorie goals or weight loss targets. Since participants completed 1-year follow-up assessments, this type of physical activity trial is useful for assessing change in weight status among participants. A 1-year time point was selected as this is a designated time point for determining long-term maintenance of weight loss [12].

Given the importance of understanding individual variability in weight stability and response to physical activity interventions, we proposed to examine and identify evidence-based constructs associated with weight stability. Therefore, we hypothesized that psychosocial and behavioral variables, selected based on research and theory (e.g., $[8,13,27-29])$, would successfully discriminate between individuals who had different patterns of weight change over time.

\section{Materials and Method}

This study was approved by the Hospital's Institutional Review Board to ensure the adequate protections for safeguarding the rights of human subjects.

2.1. Recruitment. Recruitment consisted of a both in-person and mass media approaches, including "information booths" in local community settings, such as supermarkets and at the local community college. Additionally, flyers were distributed in the libraries, to town employees with their paychecks, and to school department employees in their mailboxes. Mass media approaches included inserts in local, regional, and special interest newspapers and public service announcements on cable-access television and radio. The recruitment message was targeted to women and included a brief overview of eligibility requirements and study purpose. Potential participants were prompted to call a toll free number to obtain information and determine eligibility and via a brief telephone screen prior to participation.

2.2. Exclusionary Criteria. Healthy, sedentary women between the ages of 18 to 65 years were recruited, with sedentary defined as participating in 90 minutes or less of purposeful physical activity or 61 minutes or less of vigorous physical activity [35]. Other exclusion criteria included medical problems that could potentially impede or be exacerbated by physical activity (e.g., history of pulmonary, cerebrovascular, cardiovascular disease, severe osteoarthritis, diabetes, BMI > 40). Physician consent was required for individuals with hypertension, murmurs, and mitral valve prolapse. In addition, individuals were excluded if there was a planned move from the area within the next year, current or planned pregnancy, hospitalization for a psychiatric disorder within the last 6 months, current suicidal or psychotic episodes, or current use of certain prescription medications (e.g., mood stabilizers, antipsychotics).

2.3. Participants. A total of 752 women responded to the recruitment strategies for the study. See Figure 1 for a participant flow chart. Of those responding, 660 were reached and screened for eligibility, with 35\% $(N=233)$ being ineligible to participate due to (1) medical conditions $(N=100)$, (2) being too active $(N=88)$, or (3) having a BMI $\geq 40(N=27)$. In addition, 18 women were excluded for "other" reasons, (e.g., age greater than 65, transportation difficulties, planned relocation, and planning to become pregnant within the next year), and 58 were not interested. Of the 369 participants who met the eligibility requirements for the study, 280 participants were randomly assigned at baseline into one of the three study arms. For these analyses, 
an $N$ of 247 will be used as this is the sample size for which we have complete BMI data at baseline and Month 12. The majority of the sample was Caucasian (94\%), middle-aged $(M=47.5 ; \mathrm{SD}=10.7)$, married (65\%), employed full-time $(53 \%)$, and underactive $(M=45.4 ; \mathrm{SD}=101.5)$. The mean BMI was 28.6 ( $\mathrm{SD} \pm 5.3)$. At baseline, there were $59(22 \%)$ normal/underweight women, 105 (39\%) overweight women, and 106 (39\%) obese women.

2.3.1. Assessments and Follow-Up Rates. The primary assessment time points were Months 3 and 12 after baseline. At these time points, participants attended an in-person assessment session and completed questionnaires and objective measures. For the purposes of these analyses, only the baseline and Month 12 values will be used. Followup rates were excellent, with $94 \%$ and $93 \%$ of the sample being retained at Month 3 and Month 12 assessment time points.

\subsection{Intervention Conditions}

2.4.1. Choose to Move ( $N=93)$. Choose to Move was a printbased booklet developed by the American Heart Association to help women adopt and maintain physical activity. The booklet was a 12-week program targeted to women, with each week covering a topic of relevance from Social Cognitive Theory and the Transtheoretical Model such as goal setting, benefits of physical activity, increasing confidence, as well as self-report logs and self-administered worksheets. No information was included regarding calorie or fat goals.

2.4.2. Jumpstart for Exercise $(N=95)$. Jumpstart was a print-based intervention that was developed and validated by researchers at the Miriam Hospital and Brown University $[38,39]$. The Jumpstart intervention consisted of tailored expert system reports and a booklet matched to Stage of Motivational Readiness for Change [38, 39]. The expert system report consisted of pre-written counseling messages on self-efficacy, barriers, benefits, social support, goal setting, and strategies for change that were provided based on information obtained from each participant [26]. Each participant in the tailored-intervention group received a mailing 4 times during the course of the 12 months (baseline, Month 1, Month 3, and Month 6). No information was included regarding calorie or fat goals.

2.4.3. Wellness $(N=92)$. Participants in this arm of the trial received one mailing that included a binder of women's health information, with no recommendations relating to physical activity or calorie/fat goals. The materials were compiled from reputable sources such as the American Cancer Society, Food and Drug Administration, USDHHS Office on Women's Health, and the National Mental Health Association. Sample topics included emotional and mental well-being and stress management.

\subsection{Measures}

2.5.1. Body Mass Index. Height and weight were obtained at the baseline and Month 12 clinic visits. Height was assessed via a stadiometer; weight was measured via a calibrated scale. BMI was calculated using the standardized formula: weight $(\mathrm{kg}) /$ height $(\mathrm{m})^{2}$. Women were categorized by weight status change from baseline to Month 12: no change (BMI within \pm 1 unit; $N=154 ; 62.4 \%$ ); increase (BMI change $\geq 1$ unit; $N=34 ; 13.8 \%$ ); decrease (BMI change $\leq 1$ unit; $N=59$; $23.9 \%$ ).

2.5.2. 7-Day Physical Activity Recall (PAR) [40]. The interviewer administered PAR $[40,41]$, was the primary outcome measure. The PAR has established validity and reliability $[40,41]$, and it has been shown to be sensitive to change in studies of moderate intensity activity (e.g., [42-44]).

2.5.3. Exercise Self-Efficacy [25]. This 5-item self-efficacy examines the respondent's confidence regarding participation in physical activity in five separate situations (e.g., vacation, bad weather, being tired, negative affect, lack of time). The scale has good internal consistency (0.82) and test-retest reliability [25].

2.5.4. Decision-Making [45]. The 16-item Decisional Balance instrument examines participants' beliefs about the costs and benefits of engaging in physical activity. Sample items include "I would feel less stressed if I were regularly physically active" and "At the end of the day, I am too exhausted to be physically active." There are two subscales one for the "pros" or benefits of being physically active and one for the "cons" or negative factors associated with being physically active. Each subscale has demonstrated reliability (coefficient alphas of 0.79 for the costs scale and 0.95 for the benefits scale).

2.5.5. Processes of Change [31]. This 40-item measure assesses the Processes of Change for physical activity. There are two factors, behavioral and cognitive processes, each consisting of five subscales. The internal consistency of the Processes of Change scales averaged 0.83 [31].

2.5.6. Social Support for Exercise [46]. This social support scale is a 14-item measure that assesses the degree to which family or friends are sources of support specific to physical activity. For the purposes of this investigation, the Participation/Involvement subscale was used. Items include "During the last three months, my family/friends have exercised with me," and "During the last three months, my family/friends gave me encouragement to stick with my exercise program." This subscale has a demonstrated testretest reliability (ranges from 0.77 to 0.79 ) and internal consistency (Cronbach's alpha ranged from 0.84 to 0.91 ) [46].

2.5.7. Perceived Stress Scale (PSS) [47]. This 14-item measure assessed the extent to which a participant evaluated different situations as stressful (e.g., "In the last week, how often have 


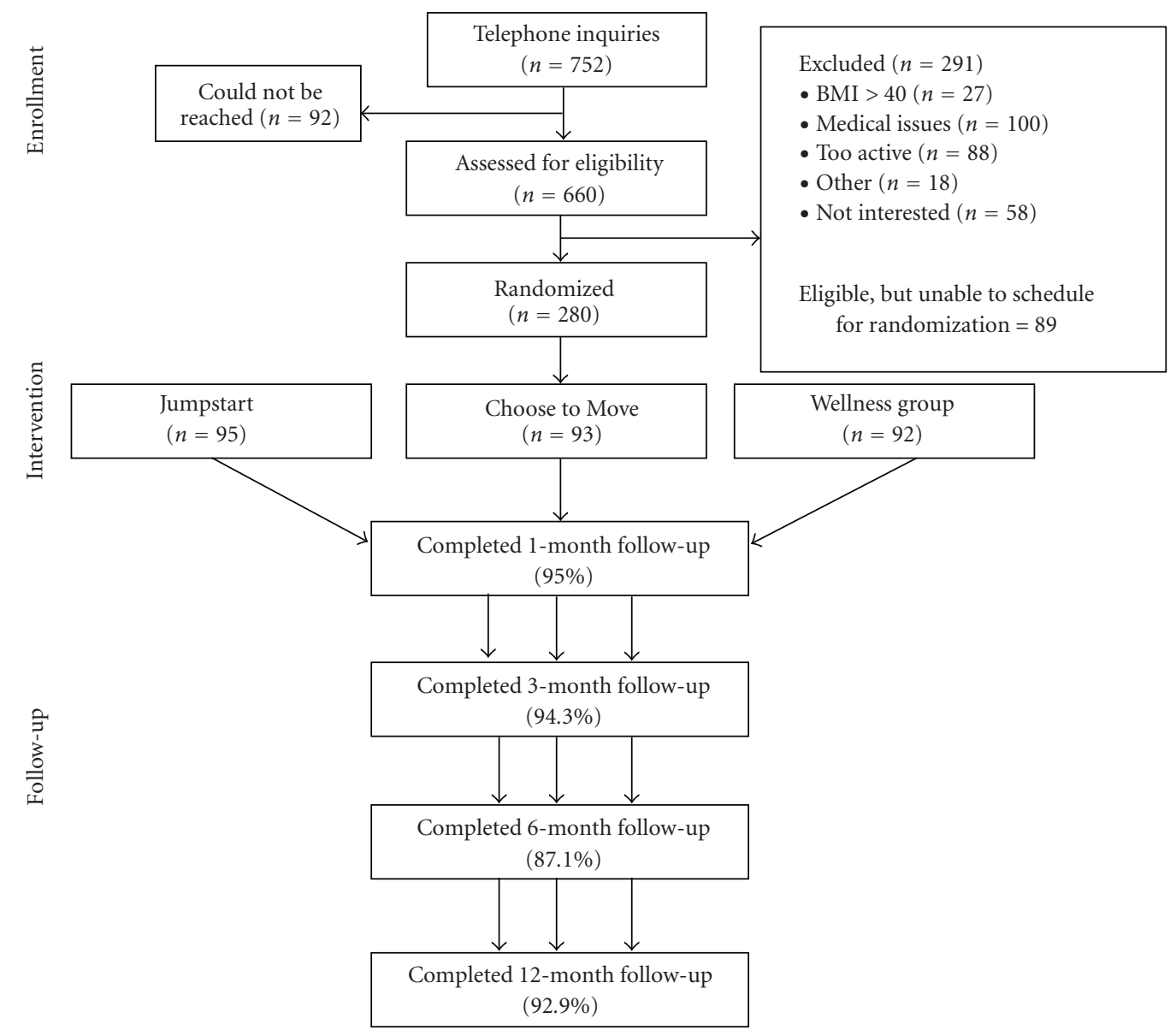

Figure 1: Participant flow chart.

you felt that you were unable to control the important things is your life."). The Perceived Stress scale has been shown to have good reliability and validity [47].

2.5.8. The Center for Epidemiologic Studies Depression Scale (CES-D) [48]. The CES-D scale is a 20-item self-report measure developed to assess depressive symptoms in the general population [48]. The CES-D scale is composed of (1) depressive affect; (2) positive affect; (3) somatic and retarded activity; (4) interpersonal problems; with $\alpha=$ .84-90. Sample items include, "I felt depressed," "I felt that I was just as good as other people," and "I felt that everything I did was an effort." The CES-D has been shown to discriminate between psychiatric inpatient and general population samples [48].

2.5.9. Sedentary Behavior [49]. For the purpose of this study, participants self-reported the number of hours spent watching television per week.

2.5.10. Fruit and Vegetable Screener [50]. The Fruit and Vegetable screener assesses 10 fruit and vegetable food items over the period of the last month. It includes items assessing the frequency of eating certain foods (e.g., fruit, juice, lettuce salad, potatoes) and the amounts consumed of each. This measure is designed to provide an estimate of the total number of Pyramid servings of fruits and vegetables consumed daily. Estimated correlations between this instrument and a recall were 0.51 for women.

2.5.11. Fat Screener [51]. The Fat Screener is a 17-item measure designed to provide an estimate of the percent of energy from fat. This measure includes items to assess the frequency a participant consumed certain foods (e.g., margarine/butter, sausage/bacon). Responses were coded and weighted in order to estimate the percent of energy from fat. This screener was validated against two 24-hour recalls collected from a nationally representative sample in the United States and a Food Frequency Questionnaire. The Fat Screener correlations with true fat intake ranged from 0.36 to 0.59 among women [51].

2.6. Analyses. All analyses were performed using SAS 9.2 [52]. A list of theoretically and research-based constructs was selected to investigate which variables discriminated weight status change (i.e., stable, gain, lose) from baseline to Month 12. Change scores were calculated with change from baseline to Month 12 on the variables of interest. First, 
a stepwise discriminant analysis was used to select the subset quantitative variables for the use of subsequent analysis to discriminate among the classes. Next, a discriminant function analysis using the variables identified in the stepwise discriminant analysis was conducted.

\section{Results}

3.1. Main Trial Results. At the 12-month follow-up, participants in all treatment arms had increased their physical activity $(M=140.4, \mathrm{SE}=14.82)$, with no differences between the arms [35]. There were no differences on key variables (i.e., age, BMI, baseline physical activity) between completers and noncompleters. Furthermore, there was no differential dropout between the groups. There also were no differences between the treatment arms on weight change $(M=-0.28$; SE $=0.09)$. Therefore, for the purpose of this paper, data will be collapsed across treatment arms.

3.2. Stepwise Discriminant Analysis. Based on the research literature of behavioral and psychological factors related to weight change (e.g., [12]) as well as theory (e.g., [27, 28]), we selected the following constructs as possible variables for use in discriminating among those women who lost, gained, or remained weight stable. The constructs were depressive symptoms, physical activity, sedentary behavior (i.e., TV watching), friend/family support for physical activity, perceived stress, cognitive and behavioral processes of change, self efficacy, decisional balance, diet composition (i.e., fruit/vegetable and fat consumption). See Table 1 for the change scores from baseline to Month 12 .

Models were run with both stepwise and forward entries, with the same cluster of variables being produced by each model. The results of the stepwise entry will be presented here. Discriminant analyses revealed depressive symptoms $(\mathrm{F}(2,223)=3.95 ; P<.05)$, physical activity behavior $(\mathrm{F}$ $(6,442)=3.09 ; P<.01)$, self-efficacy $(\mathrm{F}(4,444)=3.40$; $P<.01)$, fat consumption $(\mathrm{F}(10,438)=2.74 ; P<.01)$, and cognitive processes of change $(\mathrm{F}(8,440)=2.93 ; P<.01)$ as discriminating variables.

3.3. Discriminant Function Analysis. Tests of dimensionality indentified two distinct dimensions; both of the dimensions were statistically significant. Dimension $1(\mathrm{~F}(10,456)=$ 2.76; $P<.01)$ had a canonical correlation of 0.26 between the response variables and weight status classification, while the canonical correlation for Dimension $2(\mathrm{~F}(4,229)=$ 2.70; $P<.05)$ was lower at 0.21 . Standardized canonical coefficients for both dimensions were examined with the first dimension positively weighted by changes in mood (0.73) and self-efficacy (0.79). The second discriminant dimension was more weighted to change in physical activity (0.58) and fat consumption (0.55). The first dimension reflects a negative affect and self-confidence dimension, while the second reflects a physical activity and dietary behavior dimension. See Table 2 for the standardized pooled, within class standardized canonical coefficients, which can be interpreted similarly to standardized regression coefficients.
For example, a one standard deviation increase on the depression variable will result in a .73 standard deviation decrease in the predicted values on discriminant function 1 [53].

\section{Discussion}

The results from the discriminant function analysis indicated two statistically significant dimensions. The first dimension was a psychological dimension weighted by changes in depressive symptoms and self-efficacy for physical activity. When examining the mean changes on these variables by weight status classification, women who gained weight reported increases in depressed mood (mean $=4.47$; $S E=$ 1.58 ), compared with women who lost weight (mean = $1.30 ; \mathrm{SE}=0.95$ ) or remained weight stable (mean $=0.47$; $\mathrm{SE}=0.66)$. This finding is consistent with other studies in which depressive symptomatology was negatively associated with weight regain [12]. There are a few explanations for the association between mood and weight. Successful and purposeful weight loss is associated with improved mood $[17,18]$. Other findings from a recent meta analysis suggest that there is a relationship between increased physical activity and improved mood [5]. Additionally, although psychosocial in nature, clinically, depression encompasses many physical and behavioral features. In fact, behavioral activation is often the first step in successful evidence-based treatments for depression [54]. Given the behavioral components of depression, it is not surprising that depressive symptoms also loaded at -.52 on Dimension 2. These results highlight a need to include distress tolerance or some other intervention targets for managing negative mood within the context of weight and physical activity trials.

The other variable that was weighted highly on Dimension 1 was self-efficacy for physical activity. Although the research related to the construct of self-efficacy and weight loss has been mixed [55, 56], self-efficacy has been shown to be an important construct for the adoption and maintenance of physical activity [29], and weight change in short-term weight loss studies $[27,28]$. The association between self-efficacy long-term weight outcomes from this physical activity-only trial provides further evidence for the importance of this construct. Self-efficacy is a construct that reflects one's confidence that they can be active despite numerous barriers $[23,57]$. While self-efficacy tends to be domain specific $[57,58]$, there is likely overlap between one's confidence to be physically active and their confidence to perform other healthy weight-related behaviors. It is interesting to note the change scores for this construct by weight status. For women classified as losing or gaining weight, the mean change was about 0.33 . However, for women classified as being weight stable, there was virtually no change on self-efficacy between baseline and Month 12 $(M=-0.02)$. Women who have successfully performed physical activity for a 12-month period may have already internalized their confidence to do so, which may reflect the stability of that construct over time among women who were weight stable. Future studies should investigate 
TABLE 1: Change scores by 12-month weight status.

\begin{tabular}{|c|c|c|c|c|c|c|c|c|c|}
\hline \multirow{2}{*}{ Variable } & \multicolumn{3}{|c|}{ Gain } & \multicolumn{3}{|c|}{ Lose } & \multicolumn{3}{|c|}{ Weight stable } \\
\hline & $N$ & Mean & Std error & $N$ & Mean & Std error & $N$ & Mean & Std error \\
\hline Depressed mood* & 34 & 4.47 & 1.58 & 58 & 1.30 & 0.95 & 152 & 0.47 & 0.66 \\
\hline PA behavior* & 34 & 92.79 & 46.96 & 59 & 170.02 & 37.27 & 154 & 95.90 & 11.21 \\
\hline Perceived stress & 33 & 1.00 & 1.21 & 58 & 0.88 & 0.91 & 152 & -0.56 & 0.58 \\
\hline Beh. proc of change & 34 & 0.21 & 0.12 & 59 & 0.28 & 0.09 & 151 & 0.17 & 0.05 \\
\hline Cog proc of change* & 34 & -0.04 & 0.10 & 59 & -0.16 & 0.08 & 151 & -0.12 & 0.05 \\
\hline TV viewing & 33 & -2.15 & 2.56 & 58 & -2.26 & 2.47 & 151 & 0.42 & 1.28 \\
\hline Self-efficacy* & 34 & 0.34 & 0.16 & 59 & 0.32 & 0.14 & 151 & -0.02 & 0.07 \\
\hline Decisional balance-pros & 34 & -0.30 & 0.12 & 59 & -0.11 & 0.10 & 151 & -0.21 & 0.06 \\
\hline Decisional balance-cons & 34 & -0.03 & 0.13 & 59 & -0.16 & 0.09 & 151 & 0.07 & 0.06 \\
\hline Social support-PA, friends & 33 & 1.88 & 1.85 & 56 & 1.25 & 0.96 & 149 & 0.30 & 0.58 \\
\hline Social support-PA, family & 34 & 2.79 & 1.92 & 57 & 2.28 & 1.10 & 148 & 1.59 & 0.56 \\
\hline Fruit consumption & 33 & -0.55 & 0.70 & 58 & 0.58 & 0.36 & 153 & 0.06 & 0.29 \\
\hline Fat consumption* & 32 & -1.80 & 0.71 & 55 & -0.32 & 0.66 & 149 & -1.03 & 0.32 \\
\hline
\end{tabular}

Note. ${ }^{*}$ Indicates variables identified in stepwise discriminant analysis.

TABLE 2: Canonical coefficients associated with each variable.

\begin{tabular}{lcc}
\hline & $\begin{array}{c}\text { Pooled Within-Class Standardized } \\
\text { Canonical Coefficients } \\
\text { Dimension 1 }\end{array}$ & Dimension 2 \\
\hline Variable & & \\
$\quad$ Depressed Mood & 0.73 & -0.52 \\
PA Behavior & 0.35 & 0.58 \\
Cog Proc of & -0.37 & -0.37 \\
Change & 0.79 & 0.11 \\
Self-efficacy & 0.04 & 0.55 \\
Fat consumption & & \\
\hline
\end{tabular}

the longitudinal relationship between changes in physical activity self-efficacy and weight gain. For women who are gaining weight, confidence in their ability to exercise may not transfer to confidence for managing dietary behaviors.

The second dimension identified in the discriminant function analysis reflects a behavior dimension. Consistent with other studies, these results provide further evidence for the importance of behavior change (i.e., physical activity and diet) in long-term weight maintenance. In particular, women who lost weight reported, on average, 170 minutes of physical activity, in contrast to the amounts reported (93 and 96 minutes) in women who gained and remained weight stable, respectively. This result is similar to other studies indicating that physical activity behavior distinguishes successful weight loss maintainers [13]. Consumption of a low-fat diet has been shown to be an important behavioral target for weight loss/maintenance, as well (e.g., [14]). Findings from the discriminant function analysis also identify fat consumption as a distinguishing variable. However, when the means are examined, women who gained weight reported lower $(-1.80)$ fat consumption compared with women who lost $(-0.32)$ or remained weight stable $(-1.03)$. It is surprising that women who gained weight from baseline to Month 12 reported greater decreases in fat consumption than women who lost or remained weight stable. This could reflect a tendency for underreporting [59-61] or a social desirability bias $[62,63]$ that women who gained weight may be embarrassed by their dietary intake and thus were not forthcoming about their intake. Unsuccessful dieters have been shown to misreport (i.e., underestimate) their intake by $47 \%$ compared with $19 \%$ of controls [61]. It is likely the results of the current study are related to a reporting bias, which is consistent with other studies which have found selective underreporting of fat by obese participants $[60,64]$. Future studies should include more precise measures of dietary intake and behavior than the screener measure used in this study.

There are some limitations of this study which would put the findings in context. First, although weight and height were clinically measured and physical activity was assessed via an interviewer-based measure, the other measures were self-reported. A particular limitation of the measurement is the use of fruit/vegetable and fat consumption screener measures, rather than a food frequency questionnaire [65]. A more complete measure of dietary intake may have resulted in different findings for eating behaviors. Additionally, the study sample was all female and predominately Caucasian, therefore the results cannot be generalized to men nor to other races/ethnicities. Of the sample, only $13.8 \%$ gained weight over the 12-month period; despite this small number inclusion of this group provides an important comparison for the study. Finally, the participants were self-selected in that they were interested and willing to be part of a physical activity intervention trial. Anecdotally, many of the women reported joining the trial with the goal of losing weight. It is possible that the women were motivated, in general, to lose weight, and this could have influenced the associations found in this study. Nonetheless, a physical activity-only intervention trial, particularly one with $>90 \%$ retention rates, provides a useful context for examining longterm weight change. This retrospective longitudinal analysis 
provides a framework for examining patterns of change that can be generalized to individuals who have not had the benefit of dietary recommendations, calorie goals, and problem solving for high risk situations, as is typical for behavioral weight control interventions.

Although the variables selected for inclusion in the analyses were based on theory and evidence-based practice, the study was retrospective in design, consisting of post hoc analyses. Discriminant function analyses have great potential value, particularly in the retrospective examination of certain predictor variables [66], but have limitations. Specifically, this approach does not allow for the examination of directionality of changes nor reverse causality. For the current study, there were other variables known as important for weight loss maintenance not included in the discriminant analyses as they were not measured in the present study. Future studies should examine other psychosocial and behavioral variables of interest.

Despite these limitations, however, the paper identifies important constructs related to weight stability. This study provides further evidence for the importance of behavior in long-term weight maintenance, particularly physical activity and dietary fat consumption. These findings also provide evidence for the importance of psychosocial variables, in particular depressed mood and self-efficacy. These results give investigators signals as to the variables of importance for targeting in future physical activity trials. Not only are they important in physical activity trials, but also for weight trials. Approximately $24 \%$ of the sample lost weight (at least 1 BMI unit) over the 12-month period, despite the lack of a calorie goal, weight loss problem solving, and behavioral weight control content. Thus, almost $1 / 4$ of women in this trial were independently making changes to be successful at weight management without the benefit of direct education and skills provided within the context of behavioral weight loss. Therefore, it is essential to better understand the strategies and steps these women are employing to learn to extend to other individuals. Better understanding of the intermediate steps women take to lose and maintain weight over a 1-year period can help elucidate the critical mechanisms for successful weight loss and maintenance.

There also are implications for the design and content of both weight management and physical activity interventions. In particular, future interventions should continue to provide education and strategies for improving selfefficacy [67], particularly in the context of weight loss and maintenance [68]. Such strategies include "modeling" or watching others perform the behavior, practicing and mastering the behavior in situations previously thought insurmountable, modifying and reinterpreting physiological states (e.g., aches/pains) to something positive (e.g., "I must be building muscle mass") $[68,69]$. Additionally, while treating depression may be outside of the expertise of health promotion professionals, interventions can still provide tools for helping patients improve mood and manage distress. In particular, mindfulness-based approaches to diet and physical activity are promising adjuncts to traditional behavioral weight control interventions $[69,70]$.
With the high rates of obesity [71-73], there is emerging focus on the importance of understanding individual responses to physical activity and weight loss trials. This study sheds light on individual variables that may help explain why some people experience different longterm patterns of weight change. These variables also are important for understanding the mechanisms by which individuals maintain long-term weight losses. Future studies are needed to replicate these findings in physical activity intervention trials, as these trials provide a controlled way for understanding what individuals are doing outside of the context of weight loss trials, which is more reflective of the general population. The results from this study provide further evidence of the importance of continuing to refine our behavior change interventions to assure that they contain the most relevant content and theory-based skill building. By providing this information and skill building, the negative and psychological consequences of weight gain can potentially be averted.

\section{Acknowledgments}

This project was supported by a Grant from the Robert Wood Johnson Foundation (RWJF\#044224). The authors would like to thank the following coinvestigators for their input on the design, implementation, and execution of the project: Anna Albrecht, Bess H. Marcus, Christopher Sciamanna, and Jessica A. Whiteley, as well as Terry Bazzarre of the Robert Wood Johnson Foundation for his support of this project. The American Heart Association provided the Choose to Move materials in kind. Additionally, they would like to acknowledge the dedicated staff on the project: Melanie Bouchard, Holly Escudero, Nancy Farrell, Paul Elsnau, Cary Garcia, Meghan Harwood, Susan Pinheiro, Janice Tripolone, Yunxia Sui and Kate Williams. Finally, they would like to thank Allison Ives and Jessica Colucci for their help with the paper preparation.

\section{References}

[1] W. J. Brown, N. W. Burton, and P. J. Rowan, "Updating the evidence on physical activity and health in women," American Journal of Preventive Medicine, vol. 33, no. 5, pp. 404-411.e25, 2007.

[2] J. Bucksch and W. Schlicht, "Health-enhancing physical activity and the prevention of chronic diseases - an epidemiological review," Sozial- und Praventivmedizin, vol. 51, no. 5, pp. 281-301, 2006.

[3] S. N. Blair and J. N. Morris, "Healthy hearts-and the universal benefits of being physically active: physical activity and health," Annals of Epidemiology, vol. 19, no. 4, pp. 253256, 2009.

[4] W. L. Haskell, S. N. Blair, and J. O. Hill, "Physical activity: health outcomes and importance for public health policy," Preventive Medicine, vol. 49, no. 4, pp. 280-282, 2009.

[5] V. S. Conn, "Depressive symptom outcomes of physical activity interventions: meta-analysis findings," Annals of Behavioral Medicine, vol. 39, no. 2, pp. 128-138, 2010. 
[6] A. Deslandes, H. Moraes, C. Ferreira et al., "Exercise and mental health: many reasons to move," Neuropsychobiology, vol. 59, no. 4, pp. 191-198, 2009.

[7] J. H. Goldberg and A. C. King, "Physical activity and weight management across the lifespan," Annual Review of Public Health, vol. 28, pp. 145-170, 2007.

[8] J. E. Donnelly, S. N. Blair, J. M. Jakicic, M. M. Manore, J. W. Rankin, and B. K. Smith, "Appropriate physical activity intervention strategies for weight loss and prevention of weight regain for adults," Medicine and Science in Sports and Exercise, vol. 41, no. 2, pp. 459-471, 2009.

[9] W. L. Haskell, I. M. Lee, R. R. Pate et al., "Physical activity and public health: Updated recommendation for adults from the American College of Sports Medicine and the American Heart Association," Circulation, vol. 116, no. 9, pp. 1081-1093, 2007.

[10] J. M. Jakicic, "The effect of physical activity on body weight," Obesity, vol. 17, no. 3, pp. S34-S38, 2009.

[11] J. M. Jakicic, B. H. Marcus, W. Lang, and C. Janney, "Effect of exercise on 24-month weight loss maintenance in overweight women," Archives of Internal Medicine, vol. 168, no. 14, pp. 1550-1559, 2008.

[12] R. R. Wing and S. Phelan, "Long-term weight loss maintenance," The American journal of clinical nutrition, vol. 82, no. 1, pp. 222S-225S, 2005.

[13] S. Phelan, T. Liu, A. Gorin et al., "What distinguishes weightloss maintainers from the treatment-seeking obese? Analysis of environmental, behavioral, and psychosocial variables in diverse populations," Annals of Behavioral Medicine, vol. 38, no. 2, pp. 94-104, 2009.

[14] D. S. Bond, S. Phelan, T. M. Leahey, J. O. Hill, and R. R. Wing, "Weight-loss maintenance in successful weight losers: surgical vs non-surgical methods," International Journal of Obesity, vol. 33, no. 1, pp. 173-180, 2009.

[15] J. Kruger, H. M. Blanck, and C. Gillespie, "Dietary practices, dining out behavior, and physical activity correlates of weight loss maintenance," Preventing Chronic Disease, vol. 5, no. 1, p. A11, 2008.

[16] B. L. Needham, E. S. Epel, N. E. Adler, and C. Kiefe, "Trajectories of change in obesity and symptoms of depression: the cardia study," American Journal of Public Health, vol. 100, no. 6, pp. 1040-1046, 2010.

[17] J. Kerr, K. Patrick, G. Norman et al., "Randomized control trial of a behavioral intervention for overweight women: impact on depressive symptoms," Depression and Anxiety, vol. 25, no. 7, pp. 555-558, 2008.

[18] J. B. Dixon, M. E. Dixon, and P. E. O’Brien, "Depression in association with severe obesity: changes with weight loss," Archives of Internal Medicine, vol. 163, no. 17, pp. 2058-2065, 2003.

[19] L. M. Delahanty, J. B. Meigs, D. Hayden, D. A. Williamson, and D. M. Nathan, "Psychological and behavioral correlates of baseline BMI in the Diabetes Prevention Program (DPP)," Diabetes Care, vol. 25, no. 11, pp. 1992-1998, 2002.

[20] K. H. C. Kim, Z. Bursac, V. DiLillo, D. B. White, and D. S. West, "Stress, race, and body weight," Health Psychology, vol. 28, no. 1, pp. 131-135, 2009.

[21] K. Lahiri, V. Rettig-Ewen, M. Böhm, and U. Laufs, "Perceived psychosocial stress and cardiovascular risk factors in obese and non-obese patients," Clinical Research in Cardiology, vol. 96, no. 6, pp. 365-374, 2007.

[22] E. S. Anderson, J. R. Wojcik, R. A. Winett, and D. M. Williams, "Social-cognitive determinants of physical activity: the influence of social support, self-efficacy, outcome expectations, and self-regulation among participants in a church-based health promotion study," Health Psychology, vol. 25, no. 4, pp. 510520, 2006.

[23] A. Bandura, Social Foundations of Thought and Action: A Social Cognitive Theory, Prentiss-Hall, Englewood Cliffs, NJ, USA, 1986.

[24] J. O. Prochaska and C. C. DiClemente, "Stages and processes of self-change of smoking: toward an integrative model of change," Journal of Consulting and Clinical Psychology, vol. 51, no. 3, pp. 390-395, 1983.

[25] B. H. Marcus, V. C. Selby, R. S. Niaura, and J. S. Rossi, "Selfefficacy and the stages of exercise behavior change," Research Quarterly for Exercise and Sport, vol. 63, no. 1, pp. 60-66, 1992.

[26] M. A. Napolitano and B. H. Marcus, "Targeting and tailoring physical activity information using print and information technologies," Exercise and Sport Sciences Reviews, vol. 30, no. 3, pp. 122-128, 2002.

[27] K. I. Gallagher, J. M. Jakicic, M. A. Napolitano, and B. H. Marcus, "Psychosocial factors related to physical activity and weight loss in overweight women," Medicine and Science in Sports and Exercise, vol. 38, no. 5, pp. 971-980, 2006.

[28] P. J. Teixeira, S. B. Going, L. B. Houtkooper et al., "Pretreatment predictors of attrition and successful weight management in women," International Journal of Obesity, vol. 28, no. 9, pp. 1124-1133, 2004.

[29] M. A. Napolitano, G. D. Papandonatos, B. A. Lewis et al., "Mediators of physical activity behavior change: a multivariate approach," Health Psychology, vol. 27, no. 4, pp. 409-418, 2008.

[30] J. S. Rossi, S. R. Rossi, W. F. Velicer, and J. O. Prochaska, “To change or not to change: that is the question," in Handbook of the Assessment Methods for Eating Behaviors and Weight Related Problems, D. B. Allison, Ed., pp. 387-430, Sage, Newbury Park, Calif, USA, 1995.

[31] B. H. Marcus, J. S. Rossi, V. C. Selby, R. S. Niaura, and D. B. Abrams, "The stages and processes of exercise adoption and maintenance in a worksite sample," Health Psychology, vol. 11, no. 6, pp. 386-395, 1992.

[32] B. A. Lewis, L. H. Forsyth, B. M. Pinto, B. C. Bock, M. Roberts, and B. H. Marcus, "Psychosocial mediators of physical activity in a randomized controlled intervention trial," Journal of Sport and Exercise Psychology, vol. 28, no. 2, pp. 193-204, 2006.

[33] B. H. Marcus, M. A. Napolitano, A. C. King et al., "Telephone versus print delivery of an individualized motivationally tailored physical activity intervention: project STRIDE," Health Psychology, vol. 26, no. 4, pp. 401-409, 2007.

[34] B. H. Marcus, B. A. Lewis, D. M. Williams et al., "A comparison of internet and print-based physical activity interventions," Archives of Internal Medicine, vol. 167, no. 9, pp. 944-949, 2007.

[35] M. A. Napolitano, J. A. Whiteley, G. Papandonatos et al., "Outcomes from the women's wellness project: a communityfocused physical activity trial for women," Preventive Medicine, vol. 43, no. 6, pp. 447-453, 2006.

[36] R. Wing, "Behavioral approaches to the treatment of obesity," in Handbook of Obesity: Clinical Applications, G. Bray and C. Bouchard, Eds., pp. 147-168, Informa Healthcare, New York, NY, USA, 2008.

[37] L. G. Womble, T. A. Wadden, B. G. McGuckin, S. L. Sargent, R. A. Rothman, and E. S. Krauthamer, "A randomized controlled trial of a commercial internet weight loss program," Obesity Research, vol. 12, no. 6, pp. 1011-1018, 2004.

[38] B. H. Marcus, B. C. Bock, B. M. Pinto, L. H. Forsyth, M. B. Roberts, and R. M. Traficante, "Efficacy of an individualized, motivationally-tailored physical activity intervention," Annals of Behavioral Medicine, vol. 20, no. 3, pp. 174-180, 1998. 
[39] B. H. Marcus, K. M. Emmons, L. R. Simkin-Silverman et al., "Evaluation of motivationally tailored vs. standard self-help physical activity interventions at the workplace," American Journal of Health Promotion, vol. 12, no. 4, pp. 246-253, 1998.

[40] S. N. Blair, W. L. Haskell, and P. Ho, "Assessment of habitual physical activity by a seven-day recall in a community survey and controlled experiments," American Journal of Epidemiology, vol. 122, no. 5, pp. 794-804, 1985.

[41] J. F. Sallis, W. L. Haskell, and P. D. Wood, "Physical activity assessment methodology in the five-city project," American Journal of Epidemiology, vol. 121, no. 1, pp. 91-106, 1985.

[42] A. L. Dunn, B. H. Marcus, J. B. Kampert, M. E. Garcia, H. W. Kohl III, and S. N. Blair, "Comparison of lifestyle and structured interventions to increase physical activity and cardiorespiratory fitness: a randomized trial," Journal of the American Medical Association, vol. 281, no. 4, pp. 327-334, 1999.

[43] B. M. Pinto, M. G. Goldstein, J. Ashba, C. N. Sciamanna, and A. Jette, "Randomized controlled trial of physical activity counseling for older primary care patients," American Journal of Preventive Medicine, vol. 29, no. 4, pp. 247-255, 2005.

[44] J. F. Sallis, A. C. King, J. R. Sirard, and C. L. Albright, "Perceived environmental predictors of physical activity over 6 months in adults: activity counseling trial," Health Psychology, vol. 26, no. 6, pp. 701-709, 2007.

[45] B. H. Marcus, W. Rakowski, and J. S. Rossi, "Assessing motivational readiness and decision making for exercise," Health Psychology, vol. 11, no. 4, pp. 257-261, 1992.

[46] J. F. Sallis, R. M. Grossman, R. B. Pinski, T. L. Patterson, and P. R. Nader, "The development of scales to measure social support for diet and exercise behaviors," Preventive Medicine, vol. 16, no. 6, pp. 825-836, 1987.

[47] S. Cohen, "Perceived stress in a probability sample of the United States," in The Social Psychology of Health. The Claremont Symposium on Applied Social Psychology, S. Spacapan and S. Oskamp, Eds., pp. 31-67, Sage, Thousand Oaks, Calif, USA, 1988.

[48] L. S. Radloff, "The CES-D scale: a self-report depression scale for research in the general population," Applied Psychological Measurement, vol. 1, no. 3, pp. 385-401, 1977.

[49] R. C. Brownson, E. A. Baker, R. A. Housemann, L. K. Brennan, and S. J. Bacak, "Environmental and policy determinants of physical activity in the United States," American Journal of Public Health, vol. 91, no. 12, pp. 1995-2003, 2001.

[50] F. E. Thompson, A. F. Subar, A. F. Smith et al., "Fruit and vegetable assessment: performance of 2 new short instruments and a food frequency questionnaire," Journal of the American Dietetic Association, vol. 102, no. 12, pp. 1764-1772, 2002.

[51] F. E. Thompson, D. Midthune, G. C. Williams et al., "Evaluation of a short dietary assessment instrument for percentage energy from fat in an intervention study," Journal of Nutrition, vol. 138, no. 1, pp. 193S-199S, 2008.

[52] SAS, SAS/STAT Software 9.2 User's Guide, SAS Institute Inc., Cary, NC, USA, 2008.

[53] UCLA: Academic Technology Services, Statistical Consulting Group, "Introduction to SAS and Discriminant Analyses," October 2010, http://www.ats.ucla.edu/stat/sas/dae/discrim .htm.

[54] J. W. Kanter, R. C. Manos, W. M. Bowe, D. E. Baruch, A. M. Busch, and L. C. Rusch, "What is behavioral activation? A review of the empirical literature," Clinical Psychology Review, vol. 30, no. 6, pp. 608-620, 2010.

[55] R. W. Jeffery, "How can Health Behavior Theory be made more useful for intervention research?" International Journal of Behavioral Nutrition and Physical Activity, vol. 1, no. 1, p. 10, 2004.

[56] J. A. Linde, A. J. Rothman, A. S. Baldwin, and R. W. Jeffery, "The impact of self-efficacy on behavior change and weight change among overweight participants in a weight loss trial," Health Psychology, vol. 25, no. 3, pp. 282-291, 2006.

[57] A. Bandura, Self-Efficacy: The Excercise of Control, W. H. Freeman, New York, NY, USA, 1997.

[58] H. Leventhal, J. Weinman, E. A. Leventhal, and L. A. Phillips, "Health psychology: the search for pathways between behavior and health," Annual Review of Psychology, vol. 59, no. 1, pp. 477-505, 2008.

[59] S. D. Poppitt, D. Swann, A. E. Black, and A. M. Prentice, "Assessment of selective under-reporting of food intake by both obese and non-obese women in a metabolic facility," International Journal of Obesity, vol. 22, no. 4, pp. 303-311, 1998.

[60] A. H. C. Goris, M. S. Westerterp-Plantenga, and K. R. Westerterp, "Undereating and underrecording of habitual food intake in obese men: selective underreporting of fat intake," American Journal of Clinical Nutrition, vol. 71, no. 1, pp. 130-134, 2000.

[61] S. W. Lichtman, K. Pisarska, E. R. Berman et al., "Discrepancy between self-reported and actual caloric intake and exercise in obese subjects," New England Journal of Medicine, vol. 327, no. 27, pp. 1893-1898, 1992.

[62] J. R. Hebert, Y. Ma, L. Clemow et al., "Gender differences in social desirability and social approval bias in dietary selfreport," American Journal of Epidemiology, vol. 146, no. 12, pp. 1046-1055, 1997.

[63] J. R. Hebert, L. Clemow, L. Pbert, I. S. Ockene, and J. K. Ockene, "Social desirability bias in dietary self-report may compromise the validity of dietary intake measures," International Journal of Epidemiology, vol. 24, no. 2, pp. 389398, 1995.

[64] B. L. Heitmann and L. Lissner, "Dietary underreporting by obese individuals - is it specific or non-specific?" British Medical Journal, vol. 311, no. 7011, pp. 986-989, 1995.

[65] G. Block, M. Woods, A. Potosky, and C. Clifford, "Validation of a self-administered diet history questionnaire using multiple diet records," Journal of Clinical Epidemiology, vol. 43, no. 12, pp. 1327-1335, 1990.

[66] R. H. Lyles, Y. Guo, and A. N. Hill, "A fresh look at the discriminant function approach for estimating crude or adjusted odds ratios," American Statistician, vol. 63, no. 4, pp. 320-327, 2009.

[67] E. McAuley and B. Blissmer, "Self-efficacy determinants and consequences of physical activity," Exercise and Sport Sciences Reviews, vol. 28, no. 2, pp. 85-88, 2000.

[68] C. B. Dallow and J. Anderson, "Using self-efficacy and a transtheoretical model to develop a physical activity intervention for obese women," American Journal of Health Promotion, vol. 17, no. 6, pp. 373-381, 2003.

[69] E. M. Forman, M. L. Butryn, K. L. Hoffman, and J. D. Herbert, "An open trial of an acceptance-based behavioral intervention for weight loss," Cognitive and Behavioral Practice, vol. 16, no. 2, pp. 223-235, 2009.

[70] K. Tapper, C. Shaw, J. Ilsley, A. J. Hill, F. W. Bond, and L. Moore, "Exploratory randomised controlled trial of a mindfulness-based weight loss intervention for women," Appetite, vol. 52, no. 2, pp. 396-404, 2009.

[71] C. L. Ogden, "Disparities in obesity prevalence in the United States: black women at risk," American Journal of Clinical Nutrition, vol. 89, no. 4, pp. 1001-1002, 2009. 
[72] C. L. Ogden, M. D. Carroll, M. A. McDowell, and K. M. Flegal, "Obesity among adults in the United States-no statistically significant chance since 2003-2004," NCHS data brief, no. 1, pp. 1-8, 2007.

[73] A. A. Hedley, C. L. Ogden, C. L. Johnson, M. D. Carroll, L. R. Curtin, and K. M. Flegal, "Prevalence of overweight and obesity among US children, adolescents, and adults, 19992002," Journal of the American Medical Association, vol. 291, no. 23, pp. 2847-2850, 2004. 


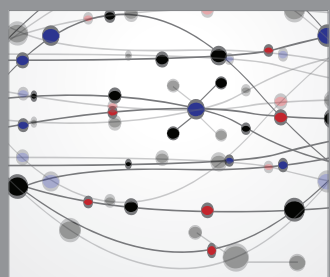

The Scientific World Journal
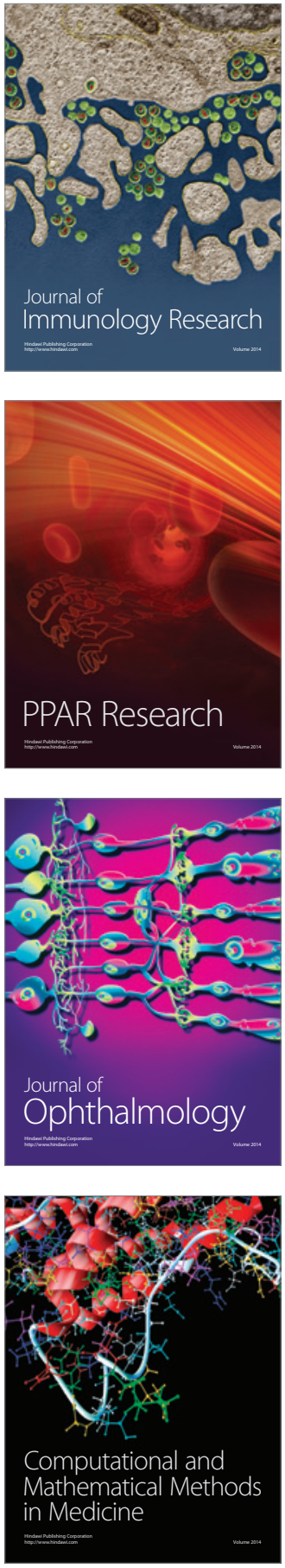

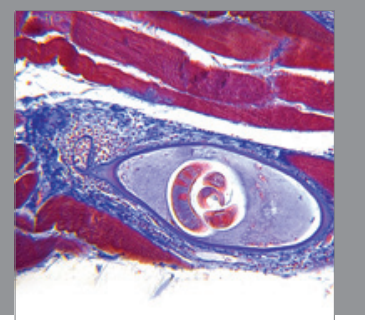

Gastroenterology

Research and Practice
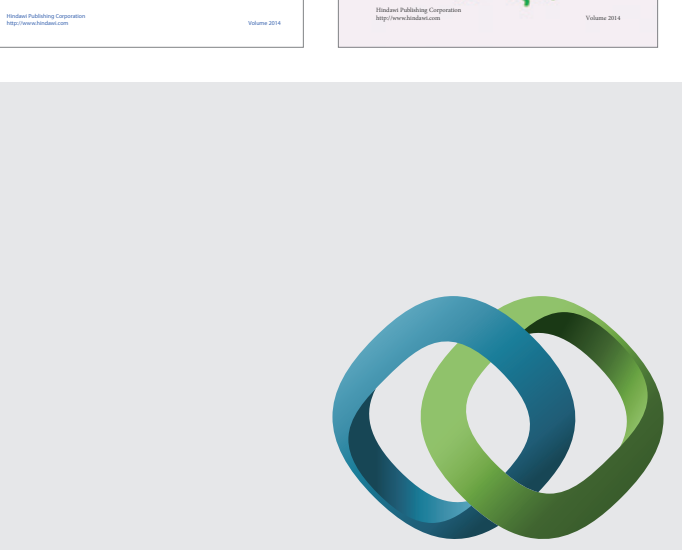

\section{Hindawi}

Submit your manuscripts at

http://www.hindawi.com
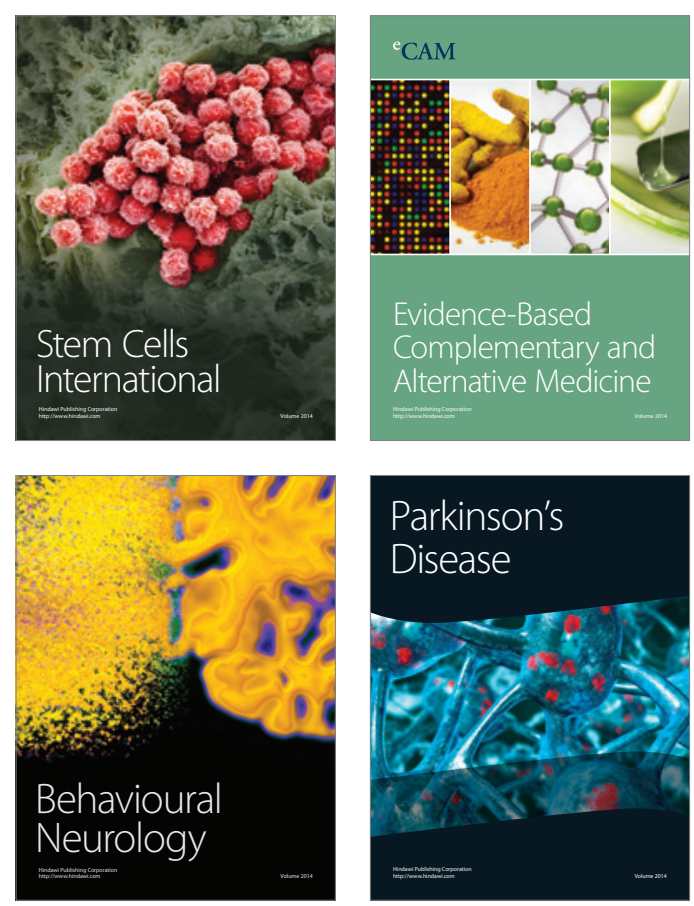

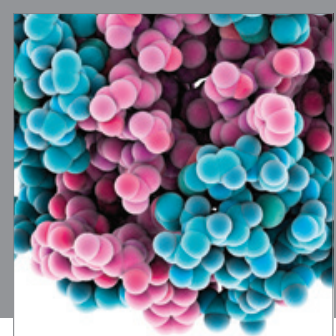

Journal of
Diabetes Research

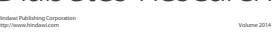

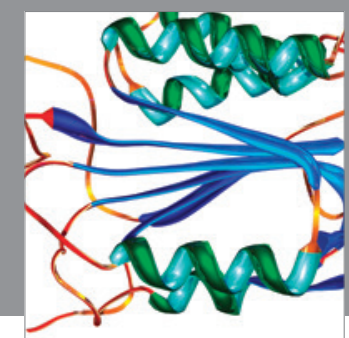

Disease Markers
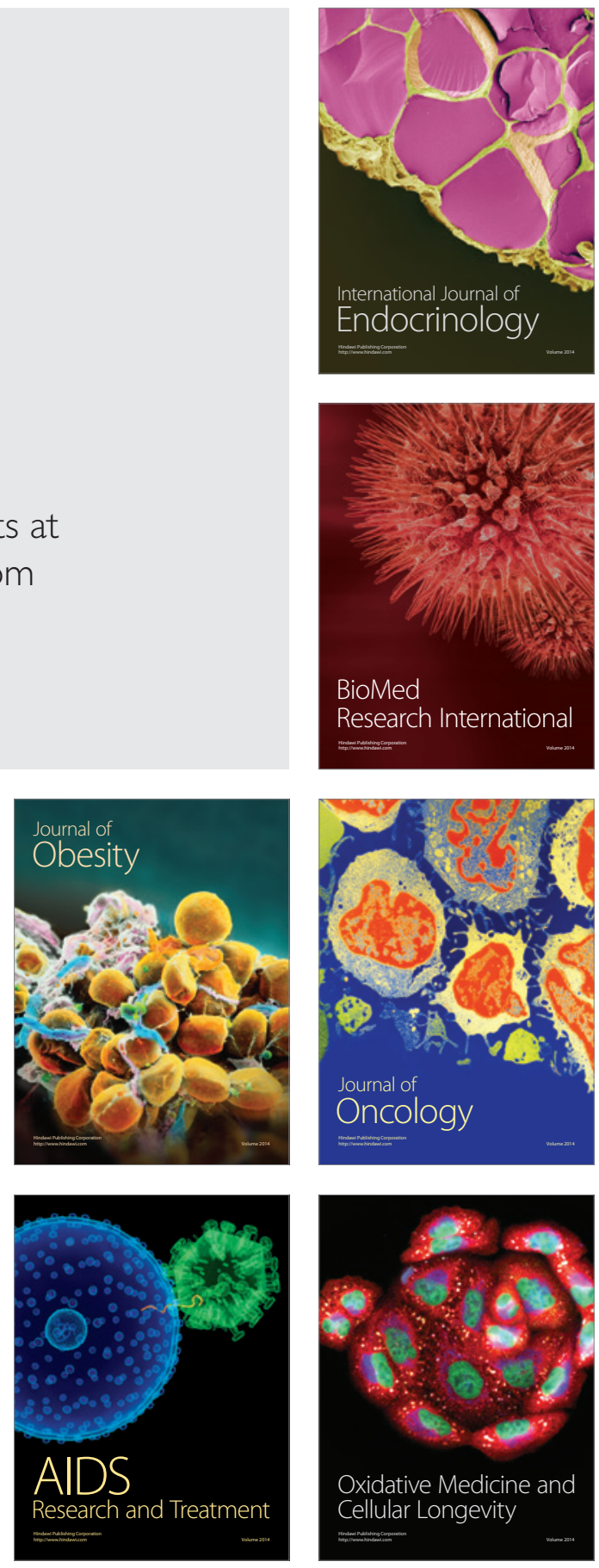